\title{
ACESSAR PARA APRENDER: AVALIAÇÃO DA ACESSIBILIDADE FÍSICA DO CAMPUS SERRA TALHADA DO IF SERTÃO-PE JUNTO À ALUNOS DO ENSINO MÉDIO
}

\author{
SILVA, Camila Coelho \\ (1) Instituto Federal do Sertão Pernambucano - IF Sertão PE, Campus Serra Talhada, \\ Mestra em Arquitetura e Urbanismo \\ e-mail: camila.coelho@ifsertao-pe.edu.br
}

\begin{abstract}
RESUMO
Sabe-se que as pessoas com deficiência enfrentam dificuldades cotidianamente, destacando-se o acesso à educação, sejam por barreiras sociais, arquitetônicas, tecnológicas ou atitudinais, muitas vezes imperceptíveis às pessoas sem deficiência. A pesquisa apresentada, em andamento, objetiva avaliar as condições de acessibilidade física do campus Serra Talhada do IF Sertão-PE, tendo como parâmetro a percepção dos alunos do ensino médio e demais usuários, bem como a legislação vigente. Acredita-se que o envolvimento dos alunos na avaliação e discussão da questão possa contribuir para conscientização desse direito e fortalecimento do exercício à cidadania, além de embasar futuras modificações do campus.
\end{abstract}

Palavras chave: Acessibilidade física; educação; conscientização.

\begin{abstract}
It is known that people with disabilities face daily difficulties, especially access to education, whether by social, architectural, technological or attitudinal barriers, often imperceptible to people without disabilities. The present research, in progress, aims to evaluate the physical accessibility conditions of the campus Serra Talhada of the IF Sertão-PE, having as a parameter the perception of high school students and other users, as well as the current legislation. It is believed that the involvement of students in the evaluation and discussion of the question can contribute to raising awareness of this right and strengthening the exercise of citizenship, as well as supporting future campus modifications.
\end{abstract}

Keywords: physical accessibility; education; awareness.

\section{INTRODUÇÃO}

De acordo com o censo realizado em 2010 pelo Instituto Brasileiro de Geografia e Estatística (SDHPR, 2012), o Brasil possui cerca de 45 milhões e 600 mil pessoas com ao menos um tipo de deficiência (23,91\%). A lei № 13.146, de 06 de julho de 2015, que institui a Lei Brasileira de Inclusão da Pessoa com Deficiência (BRASIL, 2015), em seu Art. 2o, define a pessoa com deficiência como "aquela que tem impedimento de longo prazo de natureza física, mental, intelectual ou sensorial, o qual, em interação com uma ou mais barreiras, pode obstruir sua participação plena e efetiva na sociedade em igualdade de condições com as demais pessoas". 
O Censo destaca ainda que cerca de $36 \%$ da população nordestina possui algum tipo de deficiência, sendo o estado de Pernambuco o que apresenta maior índice de pessoas com deficiência (PcD) da região Nordeste (SDHPR, 2012). Sabe-se que as PcD enfrentam dificuldades cotidianamente, destacando-se o acesso à educação, direito de todo o cidadão. A presença de barreiras sociais, arquitetônicas, tecnológicas e/ou atitudinais impede que esse direito seja alcançado em sua plenitude.

O Brasil, já na Constituição Federal de 1988 (BRASIL, 1988), apresenta uma política de inclusão social de $\mathrm{PcD}$, quando foi determinada que é competência comum da União, dos Estados, do Distrito Federal e dos Municípios, cuidar da saúde e assistência pública, da proteção e garantia das pessoas com deficiência. Posteriormente, entre outras legislações federais sobre o tema, foram sancionados a Lei no 10.098/2000 (BRASIL, 2000), que estabeleceu normas gerais e critérios básicos para a promoção da acessibilidade das pessoas portadoras de deficiência ou com mobilidade reduzida, e o Decreto 5.296/2004 (BRASIL, 2004) que estabelece que a construção, reforma ou ampliação de edificações de uso público ou coletivo, ou a mudança de destinação para estes tipos de edificação, devem ser executadas de modo que sejam ou se tornem acessíveis à pessoa com deficiência ou com mobilidade reduzida. Cabe ainda destacar que em 2015 foi criado o Estatuto da Pessoa com Deficiência (BRASIL, 2015) que garante condições de acesso à educação e à saúde e estabelece punições para atitudes discriminatórias.

Além das leis e decretos citados, vale salientar que o Brasil é um dos países participantes da Convenção sobre os direitos das Pessoas com Deficiência (PCDs) realizada em 2006 (MEC/SEESP, 2007) e aprovada pela ONU - Organização das Nações Unidas, na qual foi estabelecido que os Estados-Parte devem garantir um sistema de educação inclusiva e em todos os níveis de ensino.

Contudo, tal legislação é pouco respeitada no país, trazendo como consequências inúmeras dificuldades de locomoção e do exercício pleno da cidadania devido à falta de mobilidade e acessibilidade dos espaços urbanos e das edificações, sejam elas públicas ou privadas.

Os edifícios públicos, de maneira específica, por seu papel de prestar serviços à população, deveriam garantir a seus usuários o acesso aos diversos serviços que lhes são devidos, em sua plenitude (JOCHIMS; BINS ELY, 2015; PAIVA; VILLAROUCO, 2012), No caso das instituições de ensino, por exemplo, a cada ano, aumenta o número de pessoas com deficiência em salas de aula comuns: entre 2005 e 2015, o salto foi o equivalente a 6,5 vezes de acordo com o Censo Escolar do Inep - Instituto Nacional de Estudos e Pesquisas Educacionais Anísio Teixeira (REIS, MORENO, 2015b).

Nesse sentido, a Constituição Federal de 1988 define, no artigo 205, a educação como um direito de todos, garantindo o pleno desenvolvimento da pessoa, o exercício da cidadania e a qualificação para o trabalho. $O$ direito à educação implica na participação plena do aluno com algum tipo de deficiência no ambiente escolar, ou seja, em todas as atividades a serem desenvolvidas, sejam elas pedagógicas, esportivas ou de lazer.

Como bem explana Guerreiro (2012), observa-se nesse contexto um direito social (a educação) que demanda outros direitos para que possa ser efetivado. Assim, tem-se a acessibilidade física, que é um direito constitucional, como uma necessidade para que se possa usufruir de um direito social (GUERREIRO, 2012).

De acordo com Aranha (2004), a acessibilidade é uma das primeiras condições a permitir o acesso à escola para todos aos alunos, pois "[...] garante a possibilidade, de todos, de chegar até a escola, circular por suas dependências, utilizar funcionalmente todos os espaços, frequentar a sala de aula, nela podendo atuar nas diferentes atividades" (ARANHA, 2004, p. 21).

O Instituto Nacional de Estudos e Pesquisas Educacionais Anísio Teixeira (Inep), através do Censo Escolar 2014, revela que apenas 24\% das escolas do país oferecem boas condições 


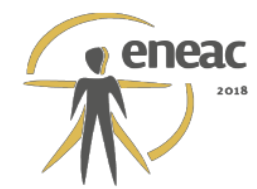

de acessibilidade para seus alunos (REIS, MORENO, 2015a). A realidade é de que três em cada quatro escolas brasileiras não contam com itens básicos de acessibilidade, como rampas, corrimãos e sinalização, e menos de um terço possui sanitários adaptados para pessoas com deficiência.

Trazendo a discussão para a realidade do Instituto Federal do Sertão Pernambucano - IF Sertão-PE, percebe-se que seus campi já apresentam alguns itens básicos de acessibilidade em sua estrutura, além de mostrarem interesse em promover a inclusão escolar e a acessibilidade através da Assistência Estudantil e do Núcleo de Apoio à Pessoa com Necessidades Específicas - NAPNE. Ainda assim, observa-se a necessidade de melhorar tal aspecto em suas estruturas físicas, partindo do desenvolvimento de estudos na área, tendo como objetos de estudo os campi do Instituto e envolvendo todos os usuários, para que ações mais práticas sejam promovidas na busca de garantir aos seus alunos e servidores, de forma plena, o acesso aos diversos serviços que lhes são devidos.

O campus Serra Talhada foi o penúltimo a ser inaugurado dentro da rede do IF Sertão-PE. O lançamento da pedra fundamental da unidade foi realizado em 10 de fevereiro de 2014 e a cerimônia de sua inauguração aconteceu no dia 30 de janeiro deste ano, 2017. Em sua estrutura física, percebem-se alguns cuidados relativos à acessibilidade física, como existência de rampas e banheiros acessíveis, embora outros não aconteçam. Neste sentido, surgem as seguintes questões: quais são as barreiras físicas do campus Serra Talhada? Como os usuários com e sem deficiência física percebem e interagem com os ambientes que compõem o Instituto? Eles percebem a (in) acessibilidade? As indicações das legislações vigentes são cumpridas?

Considerando o exposto, esta pesquisa PIBIC Jr., desenvolvida pela professora e duas alunas pesquisadoras do ensino médio, tem como objetivo geral avaliar as condições de acessibilidade física do recém-construído campus Serra Talhada do IF Sertão-PE, tendo como parâmetro a percepção dos usuários sem e com deficiência, sobretudo os alunos do ensino médio, e a legislação vigente, sobretudo a NBR 9050/2015. São objetivos específicos:

a) Discutir sobre as condições adequadas de acessibilidade física e sobre as legislações vigentes relacionadas ao tema;

b) Identificar as barreiras físicas do campus;

c) Investigar a percepção dos usuários com e sem deficiências quanto à acessibilidade e a adequação do campus às suas necessidades;

d) Avaliar a adequação dos espaços físicos do estudo às indicações da NBR 9050/2015.

Busca-se assim, partindo da perspectiva do usuário aliada à legislação vigente, tendo início no universo do campus Serra Talhada, uma sociedade menos excludente e mais inclusiva, assegurando as mesmas oportunidades para todos no sentido de poder exercer todos os direitos e liberdades fundamentais que nos foram assegurados por lei, sobretudo o acesso ilimitado à educação.

\section{MATERIAL E MÉTODOS}

A metodologia é formada por um conjunto de multitécnicas aplicadas para melhor reconhecer o tema abordado, e consequentemente o espaço físico e seu usuário, bem como as relações estabelecidas entre eles. A pesquisa é exploratória, uma vez que objetiva caracterizar e definir o problema, através de levantamento bibliográfico, entrevistas e estudo de caso. Também se apresenta como uma pesquisa de campo, onde se observam os fatos 


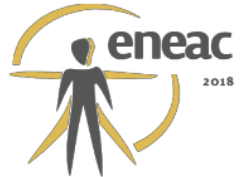

tal como ocorrem, não permite isolar e controlar variáveis, mas perceber e estudar as relações estabelecidas entre elas.

Em relação à forma de abordagem, o estudo é principalmente qualitativo, pois considera a existência de uma relação dinâmica entre o espaço e o homem. Por fim, a pesquisa é descritiva e utiliza o método indutivo.

A pesquisa é estruturada nas seguintes etapas:

1. Revisão de literatura / construção do estado da arte: A primeira etapa consistiu na revisão e crítica da literatura constituída a respeito dos conceitos, contextos, características e problemáticas que cercam o objeto de estudo deste trabalho, abordando as áreas de arquitetura e urbanismo, acessibilidade, desenho universal, instituições de ensino e legislação vigente.

2. Pesquisa documental e caracterização do objeto de estudo: foi realizado o reconhecimento do objeto de estudo a partir da pesquisa documental. Foram reunidos os projetos arquitetônicos do campus Serra Talhada do IF Sertão-PE e observadas as modificações do projeto original in loco, a fim de conhecer o dimensionamento, conexão e localização dos acessos e dos ambientes, espaços de circulação, sanitários públicos, etc. Em seguida, realizamos entrevistas semiestruturadas com cargos importantes para a compreensão das condições de acessibilidade do campus. Foram selecionados para esta etapa dois entrevistados: o diretor geral e também fiscal da obra de construção do campus, e a servidora responsável pelo Núcleo de Apoio à Pessoa com Necessidades Específicas NAPNE do campus Serra Talhada.

3. Avaliação na perspectiva do usuário: Esta etapa é constituída de duas técnicas: a vivência de acessibilidade e o passeio acompanhado. Sobre a vivência de acessibilidade, a técnica consiste em simular as deficiências em um determinado meio, não pretendendo simular todas as condições de interação com o ambiente de uma pessoa com deficiência real, mas colocar o indivíduo em uma situação de desvantagem, diferente da que está habituado, para que possa refletir sobre a temática a partir de uma experiência prática. $\mathrm{A}$ proposta, já executada, foi que os participantes, alunos do ensino médio do instituto, simulassem ter deficiência visual, mobilidade reduzida e utilizar cadeira de rodas. Já o passeio acompanhado, desenvolvido por Dischinger (2000), consiste em avaliar as condições de apreensão e uso do espaço físico partido da percepção do usuário em situações reais, observando o modo como o ambiente afeta as PcD e PMR e o comportamento destas diante das barreiras de acessibilidade. O pesquisador acompanha 0 entrevistado, sem conduzi-lo ou ajuda-lo, apenas gravando e/ou anotando as impressões e os comentários (suas e do entrevistado), transcrevendo falas importantes e fotografando eventos significativos. A técnica ainda será aplicada, em percursos constituídos de maior fluxo, maior ilegibilidade, ou maior utilização por usuários com e sem deficiência. Quanto aos participantes, serão convidados a percorrer as rotas usuários com diferentes restrições e/ou deficiências, podendo ser eles estudantes da instituição ou não: um deficiente visual, uma pessoa em cadeira de rodas, um surdo, um usuário com mobilidade reduzida e um usuário sem deficiência.

4. Comparativo do ambiente construído com a legislação vigente: Após a aplicação das técnicas supracitadas, e, observados os principais problemas de interação das pessoas com e sem deficiência real com 0 ambiente, serão identificados e registrados pelos pesquisadores os principais problemas relativos à acessibilidade do campus, à luz da legislação vigente, sobretudo da NBR 9050/2015.

5. Sistematização e análise dos dados: Por fim, todos os dados coletados serão sistematizados para melhor leitura e interpretação. A proposta é confrontar as informações adquiridas na avaliação da perspectiva dos usuários com a avaliação da legislação vigente. Objetiva-se ainda nesta etapa a indicação dos pontos mais críticos das condições de acessibilidade do campus Serra Talhada do IF Sertão-PE com possíveis soluções para que os setores responsáveis do Instituto possam executar suas adaptações, reduzindo assim 


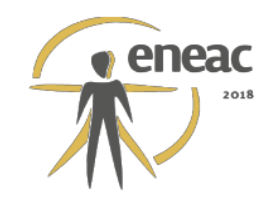

suas barreiras físicas e aproximando-se da situação ideal de acessibilidade, a ser buscada numa perspectiva futura, além da conscientização dos alunos envolvidos sobre a importância do cumprimento do direito à educação a partir da vertente da acessibilidade na escola em que estudam.

\section{RESULTADOS E DISCUSSÃO}

\subsection{Revisão de literatura e construção do estado da arte}

A pesquisa teve início com a revisão de literatura e construção do estado da arte, momento em que as alunas do ensino médio pesquisadoras puderam apropriar-se da discussão relativa à inclusão escolar e à acessibilidade, de forma geral. Também puderam ter noções básicas sobre desenho arquitetônico e projeto de arquitetura, bem como dos termos utilizados no ramo da construção civil, uma vez que não apresentam conhecimento técnico na área pelo nível de estudo em que se encontram, possibilitando a compreensão de documentos como a NBR 9050/2015 (ABNT, 2015), norma que guiará parte do projeto.

Esta fase da pesquisa teve sua importância comprovada na prova do Exame Nacional do Ensino Médio - ENEM 2017, cujo tema da redação foi "Desafios para a formação educacional dos surdos no Brasil". Uma das alunas pesquisadoras fez a avaliação e alegou ter bastante embasamento para desenvolver a redação, sobretudo devido às leituras e discussões realizadas no projeto de pesquisa.

\subsection{Pesquisa documental e Caracterização do campus}

Em seguida, partiu-se para a pesquisa documental e caracterização do campus, começando pela explicação e leitura dos projetos arquitetônicos (figura 01) e finalizando com a realização de entrevistas semiestruturadas com o diretor geral e também fiscal da obra de construção do campus, e a servidora responsável pelo Núcleo de Apoio à Pessoa com Necessidades Específicas - NAPNE do campus Serra Talhada. As entrevistas tiveram o intuito de esclarecer alguns pontos relativos ao projeto e construção de seu espaço físico, além das ações por parte do NAPNE para trabalhar as questões de acessibilidade, cujos conteúdos serão esmiuçados no corpo do texto.

Figura 01 - Alunas pesquisadoras interpretando os projetos arquitetônicos do campus Serra Talhada

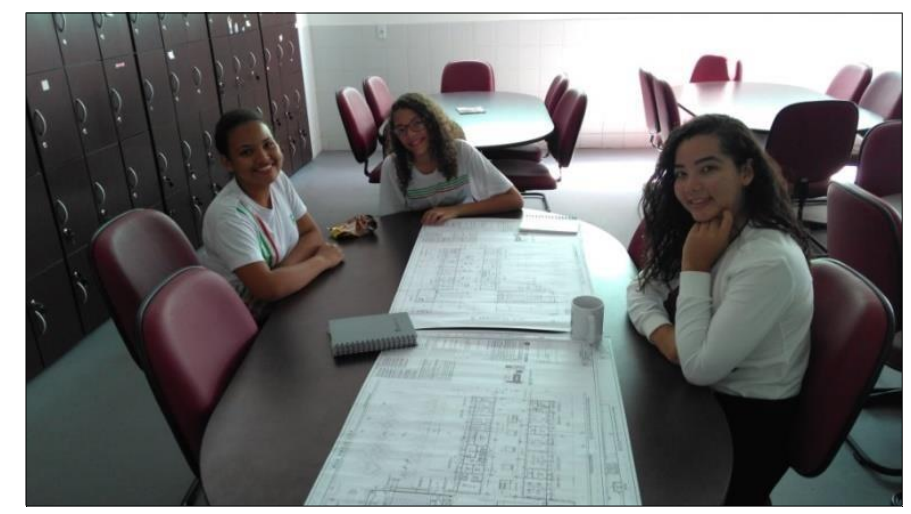

Fonte: Arquivo pessoal, 2017. 
O IF Sertão - PE, campus Serra Talhada localiza-se na Rodovia PE 360 - Km 22, Fazenda Estreito, Município de Serra Talhada-PE. O campus consta uma área construída de aproximadamente $6.000 \mathrm{~m}^{2}$, com 12 salas de aula, 06 laboratórios, banheiros, biblioteca, ginásio poliesportivo, auditório multimídia, refeitório, sala de professores/coordenação de curso 03 salas de direções. Fruto da expansão da Rede Federal de Educação Técnica e Profissional, o campus Serra Talhada oferece cursos que atendem aos alunos dos cursos de nível médio e subsequentes, Educação de Jovens e Adultos (PROEJA) e nível superior.

Segundo o atual diretor geral do campus e engenheiro civil supervisor de sua construção, o projeto arquitetônico/estrutural/instalações original parte de um modelo de projeto-padrão do Ministério da Educação - MEC para escolas da rede pública com 12 salas de aula, sendo responsável pela disponibilização de uma gama de projetos o FNDE - Fundo Nacional de Desenvolvimento da Educação.

A equipe de obras do IF Sertão PE da época utilizou um dos projetos-padrão fornecidos pelo FNDE para construção do campus Serra Talhada. O projeto foi pensado para um terreno plano e, só depois de licitada a obra, a equipe técnica visitou o terreno disponível para sua construção, quando deu início às mudanças projetuais e de execução do projeto original.

A primeira mudança observada na leitura dos projetos foi a de inversão na locação do projeto. Tendo em vista que o terreno possuía $1,8 \mathrm{~m}$ de desnível de uma extremidade à outra (diferença significativa para um terreno que deveria ser plano, segundo projeto-padrão), além de problemas surgidos durante a obra como a má compactação do solo na parte de aterro (percebida quando da tentativa de aplanar o terreno), e depois de vários estudos de viabilidade, o projeto foi espelhado no terreno, como mostrado nas figuras 02 e 03.

\section{Figura 02 - Planta esquemática - projeto} original

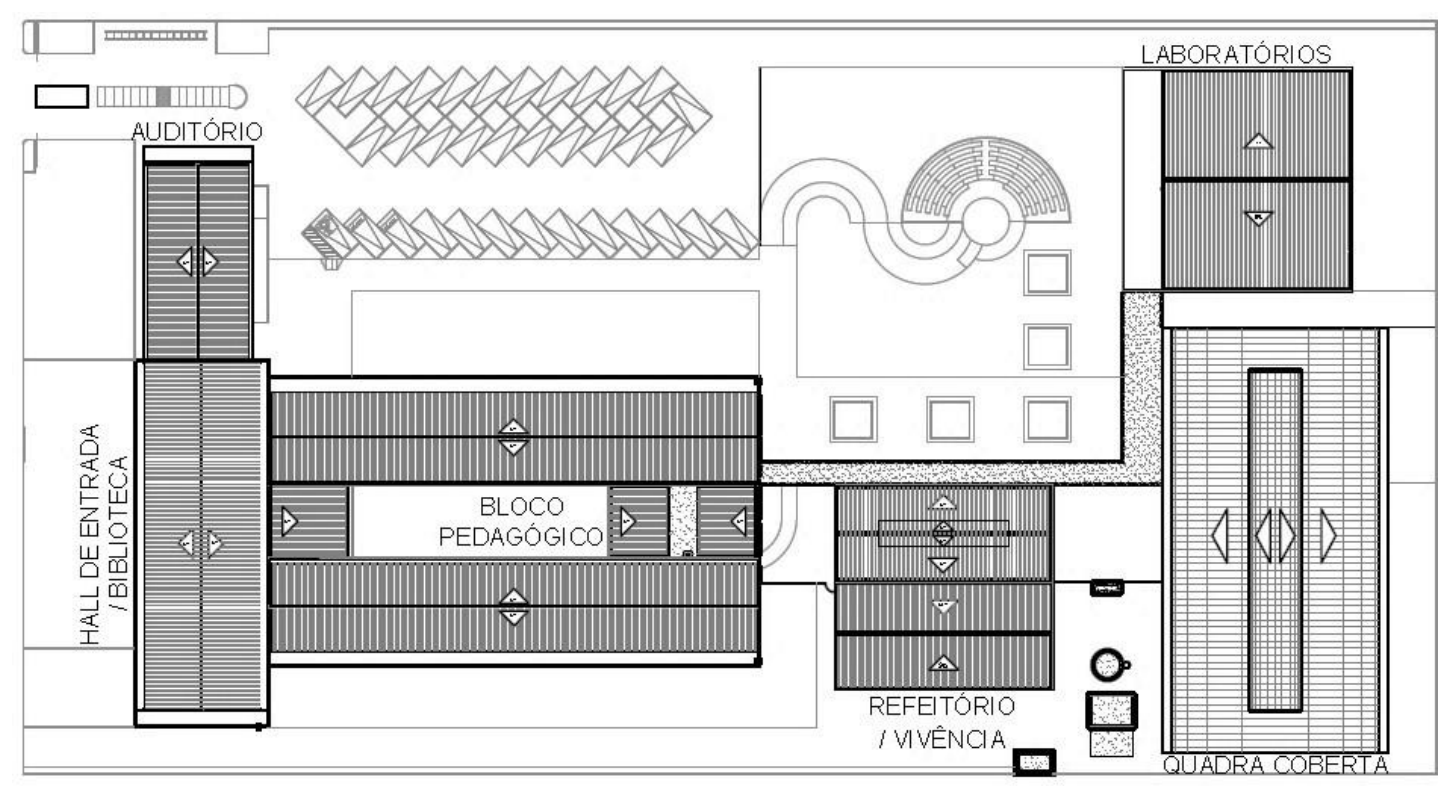

Fonte: Kleyton Michell, 2017.

Figura 03 - Planta esquemática - projeto As Built 


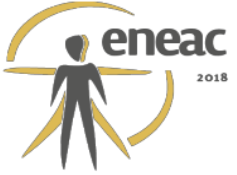

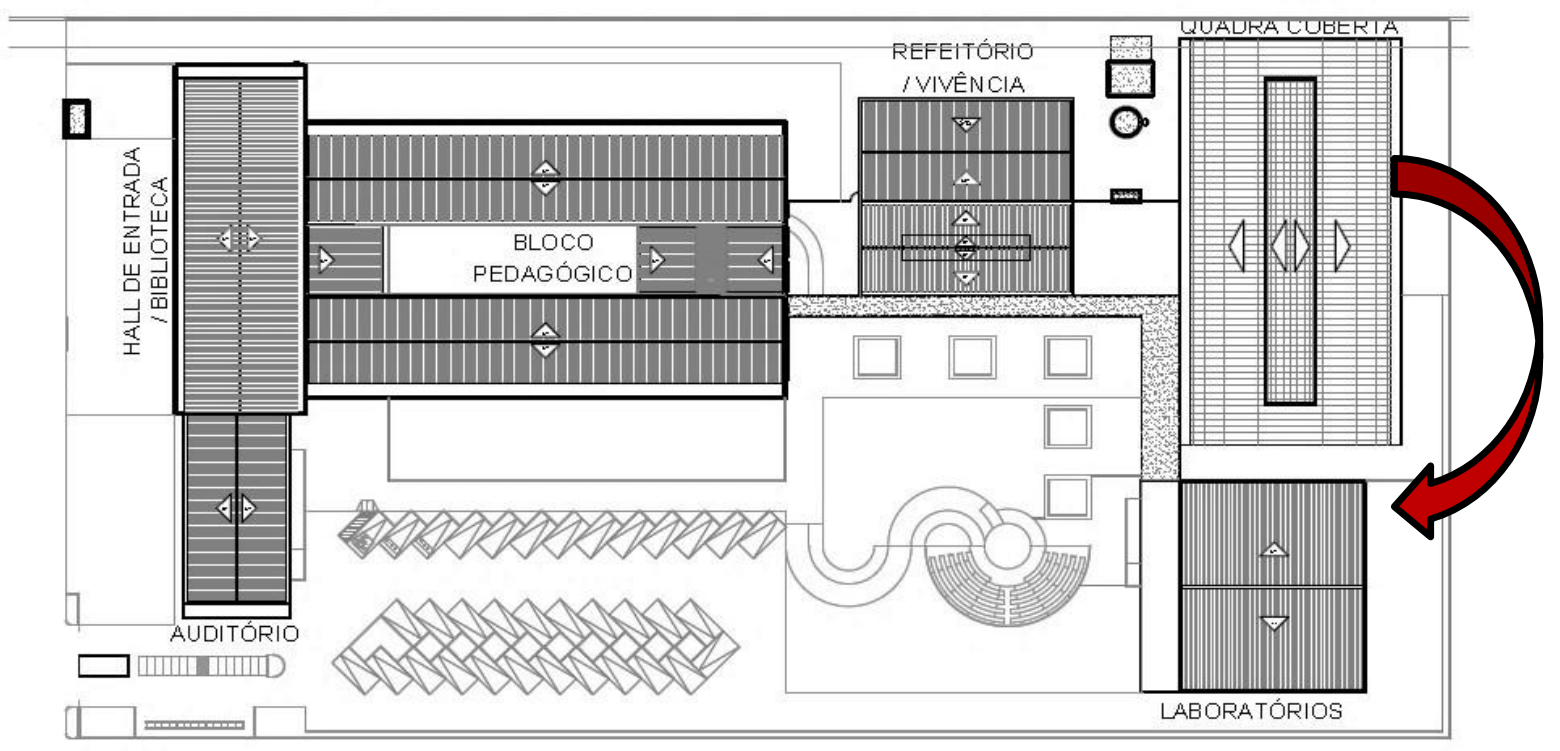

Fonte: Kleyton Michell, 2017.

Como resultado do espelhamento e do terreno de características diferentes comparado ao projeto original, algumas mudanças, acréscimos e retiradas foram necessários. As cotas dos edifícios foram modificadas para adequação ao aterro e ao corte do solo, visando à redução dos gastos, bem como a acessibilidade física no que diz respeito à criação de rampas que respeitassem a inclinação permitida. Assim, criaram-se três rampas - uma ligando o estacionamento ao auditório, outra do anfiteatro aos laboratórios especiais, e outra ligando o corredor da quadra ao espaço de convivência de frente ao refeitório.

Ainda segundo o engenheiro supervisor da obra, o projeto-padrão já vem com estudo de acessibilidade, ressaltando que o projeto é de 2009, logo seguia a versão anterior da NBR 9050 , do ano de 2004. Entretanto, observam-se alguns equívocos em seu planejamento quanto à acessibilidade física, sendo o principal a correta sinalização tátil de piso. O projeto prevê apenas sinalização de piso de alerta para entradas de ambientes e nas escadas, mas não há em nenhuma circulação o piso tátil de direção, o que inviabiliza a locomoção de um deficiente visual no campus. Esta falha foi percebida pela equipe técnica, mas, devido à falta de insumos, foi decidido que a compra dos pisos de direcionamento seria efetuada posteriormente, e, até então, não aconteceu.

Como consequência desse equívoco, não há uma rota acessível indicada no projeto original, e automaticamente no projeto As Built, ferindo a autonomia e liberdade dos usuários com deficiência no campus, bem como a NBR 9050/2015, que diz que:

Deve existir pelo menos uma rota acessível interligando o acesso de alunos às áreas administrativas, de prática esportiva, de recreação, de alimentação, salas de aula, laboratórios, bibliotecas, centros de leitura e demais ambientes pedagógicos. Todos estes ambientes devem ser acessíveis. (ABNT, 2015, p. 135)

Foram observadas ainda diversas mudanças de uso dos ambientes quando comparados os projetos original e o As Built, tendo em vista que os institutos federais têm estrutura diferenciada. Em suma, percebeu-se que, apesar de ser resultado de um projeto arquitetônico razoavelmente recente, a estrutura do campus abarca em partes os requisitos de acessibilidade física necessários para uma instituição educacional, reforçando a importância deste projeto de pesquisa. 


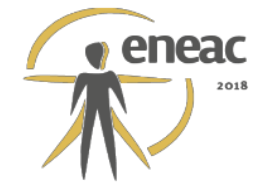

\subsection{Avaliação na perspectiva dos usuários}

O próximo passo da pesquisa é o de avaliar as condições de acessibilidade física do campus a partir do ponto de vista dos usuários. Para que o projeto possa realmente atingir seus objetivos, decidiu-se incluir os possíveis usuários à avaliação, estimulando um processo participativo, dada a importância de suas contribuições para a compreensão de suas necessidades. Nessa etapa, temos o desenvolvimento da Vivência de Acessibilidade e do Passeio Acompanhado.

A Vivência de Acessibilidade ocorreu em novembro de 2017, coordenada pela orientadora do projeto, juntamente com as alunas pesquisadoras, tendo como público participante um grupo com cerca de 10 alunos das turmas $1^{\circ}$ ano "A" e $2^{\circ}$ ano do Curso Técnico de Nível Médio Integrado em Logística. Vale salientar que todos os participantes tiveram o Termo de Consentimento Livre e Esclarecido assinados pelos pais ou responsáveis, afirmando o conhecimento dos objetivos do projeto e a permissão para utilização dos dados coletados.

Cambiaghi (2007) ressalta que a principal meta da técnica é levar cada participante a viver um conjunto de experiências interativas vinculadas à acessibilidade ao meio físico. No decorrer da vivência, os discentes revezaram quanto aos tipos de simulação de deficiências, ora como pessoas em cadeira de rodas (PCR), ora como pessoas com mobilidade reduzida (PMR) usuárias de muletas, ora como deficientes visuais.

Antes de dar início ao percurso, foram apresentadas informações básicas sobre acessibilidade física aos alunos envolvidos. Partiu-se do questionamento: a nossa escola é acessível para todos? Parte dos alunos respondeu prontamente que sim, reforçando a importância da discussão sobre o tema, e sobretudo de uma avaliação em conjunto mais profunda sobre a realidade do campus. Todas as observações relatadas a seguir foram feitas pelas alunas pesquisadoras e pelos alunos participantes da vivência.

O percurso teve início na calçada do campus, quando foi observada a inexistência do piso tátil de direcionamento. O primeiro setor visitado foi a biblioteca, onde os alunos já conseguiram perceber algumas barreiras arquitetônicas, como a entrada da biblioteca estreita para cadeirantes (figura 04), falta de pisos táteis para deficientes visuais e estantes e balcões de atendimento incapazes de atenderem a altura das pessoas em cadeira de rodas (figuras 05 e 06).

Figuras 04, 05 e 06 - Entrada da biblioteca do campus / dificuldades das PCR em relação à altura das estantes de livros e do balcão de atendimento
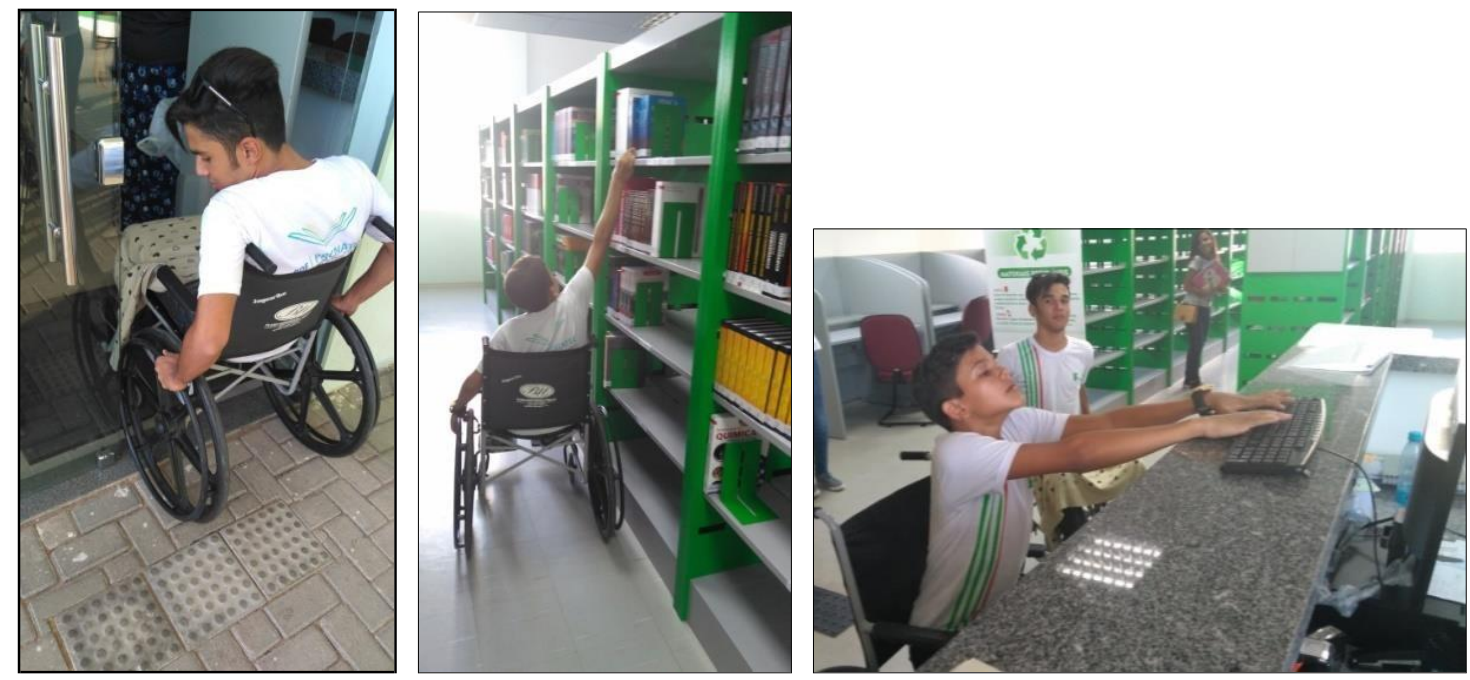

Fonte: Arquivo pessoal, 2017 


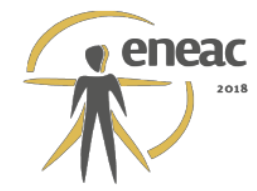

Foi constatada também a falta de uma plataforma elevatória de acesso ao segundo pavimento da biblioteca (que se dá apenas por escadas), divergindo da informação contida no projeto arquitetônico, impedindo assim o uso do espaço pelas pessoas com deficiência física e pessoas com mobilidade reduzida.

Em direção às salas de aula, localizadas no primeiro pavimento do bloco principal, comentou-se que a rampa que liga este pavimento ao térreo contém um comprimento exacerbado segundo os alunos participantes, tendo alguns deles reclamado de sua inclinação; "A rampa é muito inclinada, isso dificulta o acesso", destacou o aluno Marcus Vinicius.

As salas de aulas são expansivas e têm portas acessíveis, o que facilita as manobras cotidianas. As escadas e rampas tinham corrimãos, elementos que auxiliaram os alunos que simularam serem deficientes visuais, na falta de sinalização tátil e braile. Porém, no caminho dos banheiros foi possível perceber barreiras, como um extintor sem nenhuma sinalização ao seu redor, sendo perigoso para os deficientes visuais, além de que sua altura não se adequa às pessoas de cadeira de rodas, por ser muito alto. O aluno Sandro Filho, que simulava ser usuário de cadeira de rodas, ressalta: "se ocorrer um incêndio na escola eu não poderei ajudar".

Nos banheiros destinados às pessoas com deficiência, era possível fazer o giro de $360^{\circ}$ com a cadeira de rodas, tinham barras de apoio e espelhos inclinados, entre outros, respeitando os requisitos da acessibilidade.

No setor de administração, onde os alunos buscam contato com as coordenações de pesquisa e extensão e com o diretor geral e diretora de ensino do campus, o espaço e mobiliário eram inadequados para pessoas com cadeira de rodas e não continha piso tátil para direcionar os deficientes visuais, tornando o ambiente inacessível quase por completo.

Durante o trajeto para o refeitório, observou-se a existência de alguns obstáculos, como pisos trepidantes, barreiras e batentes sem sinalização para deficientes visuais. No refeitório percebeu-se a falta de espaço para cadeirantes nas mesas (figura 08), o que se torna constrangedor para a pessoa com deficiência, pois dificultaria sua alimentação e socialização com outras pessoas naquele espaço.

Figura 08 - Falta de espaço para cadeirantes

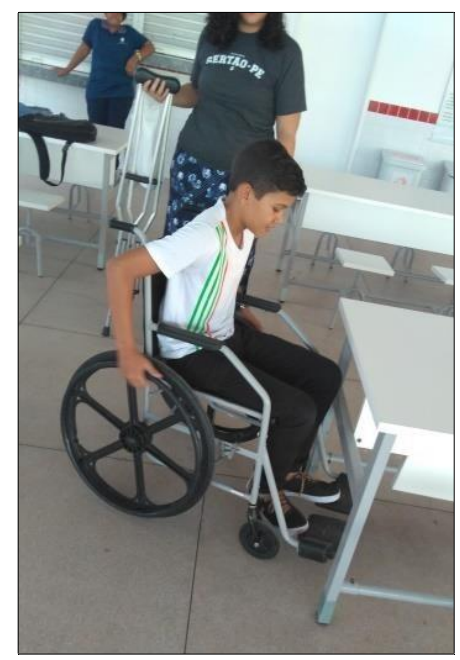

Fonte: Arquivo pessoal, 2017 


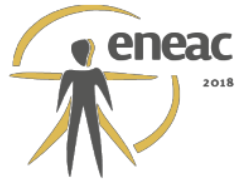

O anfiteatro, espaço localizado em frente ao refeitório e acessado através da rampa sem proteção supracitada, não possui proteção no palco bem como em sua rampa de acesso, tornando-se um dos espaços mais inseguros do campus no que diz respeito a acessibilidade física (figuras 09 e 10). Em contraponto, em sua arquibancada foi considerado o espaço necessário para os usuários de cadeiras de rodas.

Figuras 09 e 10 - Falta de proteção (corrimãos e guarda-corpo) no anfiteatro
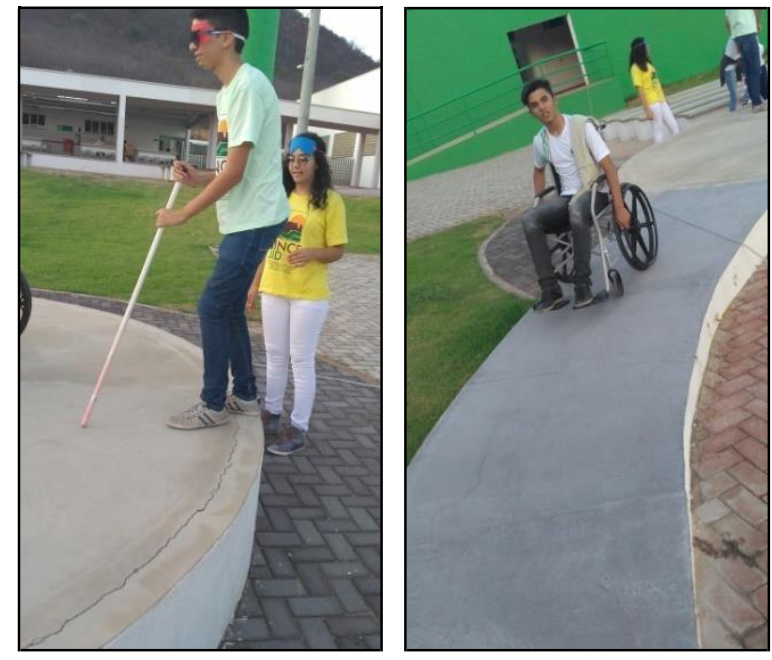

Fonte: Arquivo pessoal, 2017.

Tratando da acessibilidade na quadra poliesportiva, destaca-se que o principal impedimento é a falta de rampa/plataforma elevatória para levar cadeirantes ao segundo pavimento. Observa-se também que a arquibancada e o vestiário apresentam problemas em alguns quesitos: a arquibancada reserva um espaço para as PCR, entretanto tal espaço é isolado da arquibancada voltada para as pessoas sem deficiência, o que resulta em constrangimento para a $\mathrm{PcD}$; a ducha do vestiário não possui o banco necessário para um cadeirante tomar banho, o que impossibilita tal ação, indo contra o exigido na NBR 9050/2015, que diz que "os boxes devem ser providos de banco articulado ou removível, com cantos arredondados e superfície antiderrapante impermeável” (ABNT, 2015, p.108).

Em suma, os alunos que simularam serem deficientes visuais reclamaram sobre a falta de pisos táteis, placas em braile, direcionamentos, entre outros, em todo o campus, interferindo diretamente na segurança dos usuários: "como os deficientes visuais irão saber onde estão?" questionou a aluna Maria Eduarda. Deve-se considerar que todos os participantes já tinham uma ideia de toda rota a ser percorrida, mas, questionaram: se alguma pessoa com deficiência que nunca tivesse visitado nosso campus fosse frequentá-lo, como se localizaria na instituição?

Os alunos que simularam serem PCRs ou PMRs sentiram dificuldades basicamente em relação ao tipo de revestimento de piso de parte da escola (o piso intertravado, provavelmente devido à aplicação inadequada, provoca trepidação intensa quando utilizada a cadeira de rodas), à falta de corrimãos e guarda-corpos nas rampas e ambientes de altura como o anfiteatro, e às alturas inadequadas de alguns elementos, como estantes de livros e extintores.

O nosso campus conta com o NAPNE, porém ainda precisa de profissionais da área para complementar a equipe e proporcionar um melhor atendimento, como um intérprete de Libras, visto que só contamos com uma professora de Libras. É necessário esclarecer que, como o campus não oferece sinalização adequada nem intérprete, a Vivência de 


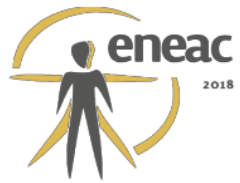

Acessibilidade não simulou tal deficiência, embora tenha constatado a inconformidade da escola neste aspecto.

O Passeio Acompanhado, relativo ainda à avaliação da acessibilidade do campus na perspectiva do usuário, será desenvolvido quando do retorno às aulas do semestre 2018.1. Até o presente momento, está sendo feito o contato com possíveis participantes voluntários para a atividade.

\section{CONCLUSÕES}

Até o presente momento, pode-se concluir através das etapas executadas na pesquisa que o Campus Serra Talhada, mesmo sendo um edifício construído recentemente e fruto de um projeto padrão fornecido pelo Ministério da Educação - MEC, apresentou várias mudanças no processo de sua idealização e, sobretudo, diversas inadequações no que diz respeito à acessibilidade física.

Tal fato nos permite afirmar antecipadamente ao fim da pesquisa que a escola não permite o acesso universal dos usuários, direito constitucional garantido aos cidadãos de forma geral. As inadequações, ausências e excessos serão mais bem definidos a partir da execução das demais etapas do projeto de pesquisa, e espera-se que se possam definir possíveis soluções junto ao diagnóstico da acessibilidade física do campus, auxiliando a resolução dos problemas identificados ou ainda a identificar no decorrer deste trabalho.

Também foi possível perceber a importância de se discutir temas relacionados à inclusão escolar, não apenas entre as alunas envolvidas na pesquisa, mas no ambiente escolar, de forma geral. O valor dessa observação pode ser comprovado com a prova do Exame Nacional do Ensino Médio - ENEM 2017, cujo tema da redação foi "Desafios para a formação educacional dos surdos no Brasil". Conhecer, vivenciar e discutir a temática é o primeiro passo para a mudança!

Busca-se nesse sentido, fortalecer a luta por uma sociedade menos excludente e mais inclusiva, assegurando os direitos de todos, sobretudo o acesso ilimitado à educação.

\section{REFERÊNCIAS BIBLIOGRÁFICAS}

ARANHA, M. S. F. Educação inclusiva - Referenciais para a construção de sistemas educacionais Inclusivos: a escola. Brasília: MEC/Secretaria de Educação Especial, 2004. v. 3.

ASSOCIAÇÃO BRASILEIRA DE NORMAS TÉCNICAS - ABNT. NBR 9050/2015: Acessibilidade a edificações, mobiliário, espaços e equipamentos urbanos. Rio de Janeiro, 2015.

BRASIL. Constituição da República Federativa do Brasil. Brasília: Imprensa Oficial, 1988.

Decreto № 5.296, de 02 de dezembro de 2004. Regulamenta as Leis nos 10.048, de 8 de novembro de 2000, que dá prioridade de atendimento às pessoas que especifica, e 10.098, de 19 de dezembro de 2000, que estabelece normas gerais e critérios básicos para a promoção da acessibilidade das pessoas portadoras de deficiência ou com mobilidade reduzida, e dá outras providências. Brasília, 2004.

Lei № 10.098, de 19 de dezembro de 2000. Estabelece normas gerais e critérios básicos para a promoção da acessibilidade das pessoas portadoras de deficiência ou com mobilidade reduzida, e dá outras providências. Brasília, 2000.

Lei № 13.146, de 06 julho de 2015. Institui a Lei Brasileira de Inclusão da Pessoa com Deficiência (Estatuto da Pessoa com Deficiência). Brasília, 2015. 


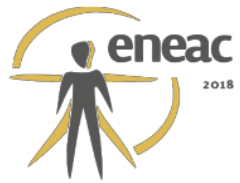

CAMBIAGHI, Silvana. Desenho universal: Métodos e Técnicas para arquitetos e urbanistas. Editora Senac São Paulo: São Paulo, 2007.

; CARLETTO, Ana C., Desenho Universal: um conceito para todos. Mara Gabrilli, 2008.

CONSELHO NACIONAL DO MINISTÉRIO PÚBLICO. Todos juntos por um Brasil mais acessível: O MP e a pessoa com deficiência. Brasília: CNMP, 2014. Disponível em: < http://www.cnmp.mp.br/portal/images/stories/Destaques/Publicacoes/ACESSIBILIDADE KM WEB.pd $\mathrm{f}>$. Acesso em: 7 maio 2017.

DISCHINGER, M. et al (Org.). Desenho Universal nas escolas: acessibilidade na rede municipal de ensino de Florianópolis. Florianópolis: PRELO, 2004. 190 p.

DISCHINGER, M.. Design for all senses: accessible spaces for visually impaired citizens. 2000. Thesis (for the degree of Doctor of Philosophy) Department of Space and Process School of Architecture, Chalmers University of Technology, Göteborg, Sweden, 2000. Disponível em:

$<$ http://publications.lib.chalmers.se/records/fulltext/1233/1233.pdf>. Acesso em: 14 abr. 2017.

GODOY, A. S.. Pesquisa qualitativa - tipos fundamentais. Revista de Administração de Empresas, São Paulo, v.35, n.3, p. 20-29. Mai. jun. 1995. Disponível em: < http://hdll.handle.net/11449/20595>. Acesso em: 30 abr. 2017.

GUERREIRO, Elaine Maria Bessa Rebello. A acessibilidade e a educação: um direito constitucional como base para um direito social da pessoa com deficiência. Rev. Educ. Espec., Santa Maria, v. 25, n. 43, p. 217-232, maio/ago. 2012. Disponível em: $<$ https://periodicos.ufsm.br/index.php/educacaoespecial >. Acesso em: 01 maio 2017.

JOCHIMS, C. E.; BINS ELY, V. H. M. Avaliação das condições de acessibilidade em um órgão público na cidade de Torres, RS. Blucher Design Proceedings, v. 2, n. 1, p. 308-319, 2015.

MEC/SEESP. Política Nacional de Educação Especial na Perspectiva da Educação Inclusiva. Documento elaborado pelo Grupo de Trabalho nomeado pela Portaria Ministerial no 555 , de 5 de junho de 2007, prorrogada pela Portaria no 948, de 09 de outubro de 2007. Disponível em:

$<$ http://portal.mec.gov.br/seesp/arquivos/pdf/politica.pdf>. Acesso em: 01 mai. 2017.

ORNSTEIN, S.; ROMERO, M. Avaliação pós-ocupação do ambiente construído. São Paulo: Studio Nobel: EDUSP, 1992.

PAIVA, M. M. B; VILLAROUCO, V. Acessibility in Collective Housing for the Elderly. Work, v. 41, p. 4174-4179, 2012.

REIS, Thiago; MORENO, Ana Carolina. 0 raio $x$ das escolas no país. Publicado em 17/08/2015a. Disponível em: <http://especiais.g1.globo.com/educacao/2015/censo-escolar-2014/o-raio-x-dasescolas-do-pais.html>. Acesso em: 06 maio 2017.

REIS, Thiago; MORENO, Ana Carolina. A escola acessível (ou não). Publicado em 19/08/2015b. Disponível em: <http://especiais.g1.globo.com/educacao/2015/censo-escolar-2014/a-escolaacessivel-ou-nao.html>. Acesso em: 06 maio 2017.

RHEINGANTZ, José Afonso; AZEVEDO, Giselle Arteiro; BRASILEIRO, Alice; ALCANTARA, Denise de; QUEIROZ, Mônica. Observando a qualidade do lugar: Procedimentos para a avaliação pósocupação. Coleção PROARQ. FAU/UFRJ. Rio de Janeiro/RJ: 2009. Disponível em: $<$ www.fau.ufrj.br/prolugar/assets/obs a qua lugar.pdf $>$. Acesso em: 14 abr. 2017.

SECRETARIA DE DIREITOS HUMANOS DA PRESIDÊNCIA DA REPÚBLICA (SDHPR). Cartilha do Censo 2010. Brasília: SDH-PR/SNPD, 2012, 32 p. 